\title{
AVOADO, NO MEIO DO PITIU: fazeres, saberes e sabores do/no rio Araí*
}

\section{AVOADO, IN THE MIDDLE OF PITIU: do, know and taste of the Araí River}

\author{
Miguel de Nazaré Brito Picanç@ ${ }^{1}$
}

O avoado diz respeito a um jeito próprio dos paraenses de assar e comer peixes, especialmente daqueles que vivem no nordeste do Pará, principalmente os que habitam o interior do estado, como no caso dos moradores, pescadores e pescadoras de Araí2. Consiste em assar o peixe (subfilo vertebrata, filo chordata) diretamente sobre a brasa, sem qualquer tipo de condimento, a não ser o sal, que em alguns casos, torna-se também dispensável. Ao mesmo tempo em que se vai assando, também se vai comendo o peixe quente, acompanhado ou de farinha d'água in natura ou de chibé e pimenta na salga de limão, dispensando-se qualquer outro acompanhamento.

Outra característica do avoado é que todos os que dele participam se colocam em volta do fogo, em círculo e normalmente de cócoras, e essa disposição dos avoadeiros é estratégica, pois facilita o acesso ao fogo no momento de alcançar o peixe para comer. Nessa prática, na maioria das vezes, dispensa-se o uso de talheres, ou seja, os alimentos são, com regularidade, manipulados diretamente com as mãos, conforme se observa nas imagens 8, 9 e 10.

Segundo seu Miguel, de 77 anos de idade, pescador e nativo de Araí, a gênese do avoado é contemporânea à necessidade de pescar, pois, desde que iniciou o ofício de pescador, há mais de 60 anos, o avoado sempre esteve presente como o principal

*Este ensaio é um recorte de minha Tese de doutorado, 2018, que foi publicada no formato livro com o título: Na roça, na mesa, na vida: uma viagem pelas trajetórias da mandioca, no e além do nordeste paraense, 2018.

1 Doutor em Ciências Sociais, pelo PPGCS da Universidade do Vale do Rio dos Sinos, na linha de pesquisa: identidade e sociabilidade, na modalidade Doutorado Sanduíche (Bolsa/CAPES), com estágio doutoral pela Universidad de Barcelona, no Observatorio de la Alimentación. Pós-doutorando pela Universidad de Barcelona, no Observatorio de la Alimentación. Compõe a equipe de pesquisadores do Laboratório de Políticas Culturais e Ambientais do Brasil (LAPCAB) onde desenvolve pesquisas no campo da Antropologia da comida e visual.

${ }^{2}$ Araí está localizada no meio rural, a $60 \mathrm{~km}$ do município de Augusto Corrêa, na região nordeste do estado do Pará. É um vilarejo com aproximadamente três mil habitantes, sendo uma das maiores comunidades rurais do município e tem como principal atividade produtiva a plantação de roça de mandioca, além do extrativismo de peixe, caranguejo (Nanoplax xanthiforms) e, principalmente, camarão (Litopenaeus vannamei). 
meio, pelo qual ele e todos os pescadores de Arai se alimentavam.

Nota-se assim, que o avoado é um recurso que, ao mesmo tempo em que alimenta os corpos dos araienses, também nutre seus laços e seus vínculos sociais. Constitui-se não somente em um momento de comer, mas também de conversar sobre os planos da pescaria e sobre outros aspectos da vida cotidiana. É um ritual comensal, que há algum tempo transcendeu as atividades pesqueiras dos rios, povoando os quintais e as mesas dos habitantes de Araí e quiçá de outros moradores das grandes cidades paraenses, como Belém 3 .

Portanto, ao que parece, o avoado opera como um marcador social (DOUGLAS; ISHERWOOD, 2006), um recurso que define uma identidade coletiva: dos pescadores avoadeiros e das populações, rurais ou não, da região do salgado paraense, funcionando como uma "carteira de identidade alimentar" (MACIEL, 2005) daqueles que pescam nos rios e habitam nessas terras do Norte.

Destarte, são inúmeros os estudos no campo da Antropologia cultural e da alimentação que confirmam essa lógica comensal inerente ao avoado, quando apontam que a comida é aquela coisa que está meticulosamente envolta com a construção das identidades coletivas. É um recurso que opera na definição dos grupos, das classes, das pessoas e das sociedades que se distinguem exatamente por suas escolhas, por suas maneiras de conceber e praticar o "de comer", ou seja, o ato de comer e a comida residem num plano muito além de uma atividade meramente biológica (PICANÇO, 2017). São práticas e coisas que agregam: "[...] Más que una colección de nutrientes elegidos de acuerdo con una racionalidad únicamente dietética o biológica. Tampoco las razones de las elecciones alimenticias son sólo económicas" (CONTRERAS, 1992, p. 98). Dito de outro modo, o ato de comer distancia-se substancialmente do ato de alimentar, na medida em que este último diz respeito apenas à função básica e imprescindível à sobrevivência humana que, por sinal, é uma função universal, enquanto o primeiro faz referência "[...] a algo costumeiro e sadio, alguma coisa que ajuda a estabelecer uma identidade, definindo, por isso mesmo, um grupo, classe ou pessoa" (DAMATTA, 1986, p.

\footnotetext{
${ }^{3}$ Com o êxodo rural, o avoado tem povoado também o cotidiano de cidades como Belém e outros centros urbanos do nordeste paraense. Nesses lugares, a ele são agregados outros elementos que 0 diferenciam dos modos de fazê-lo e de comê-lo em Araí e nas demais comunidades rurais do salgado paraense.
} 
55).

Desse modo, são das experiências comensais, mediadas pelo avoado dos pescadores de Araí, que "falam" as fotografias deste ensaio e nos convidam a pensar essa prática singular de comer.

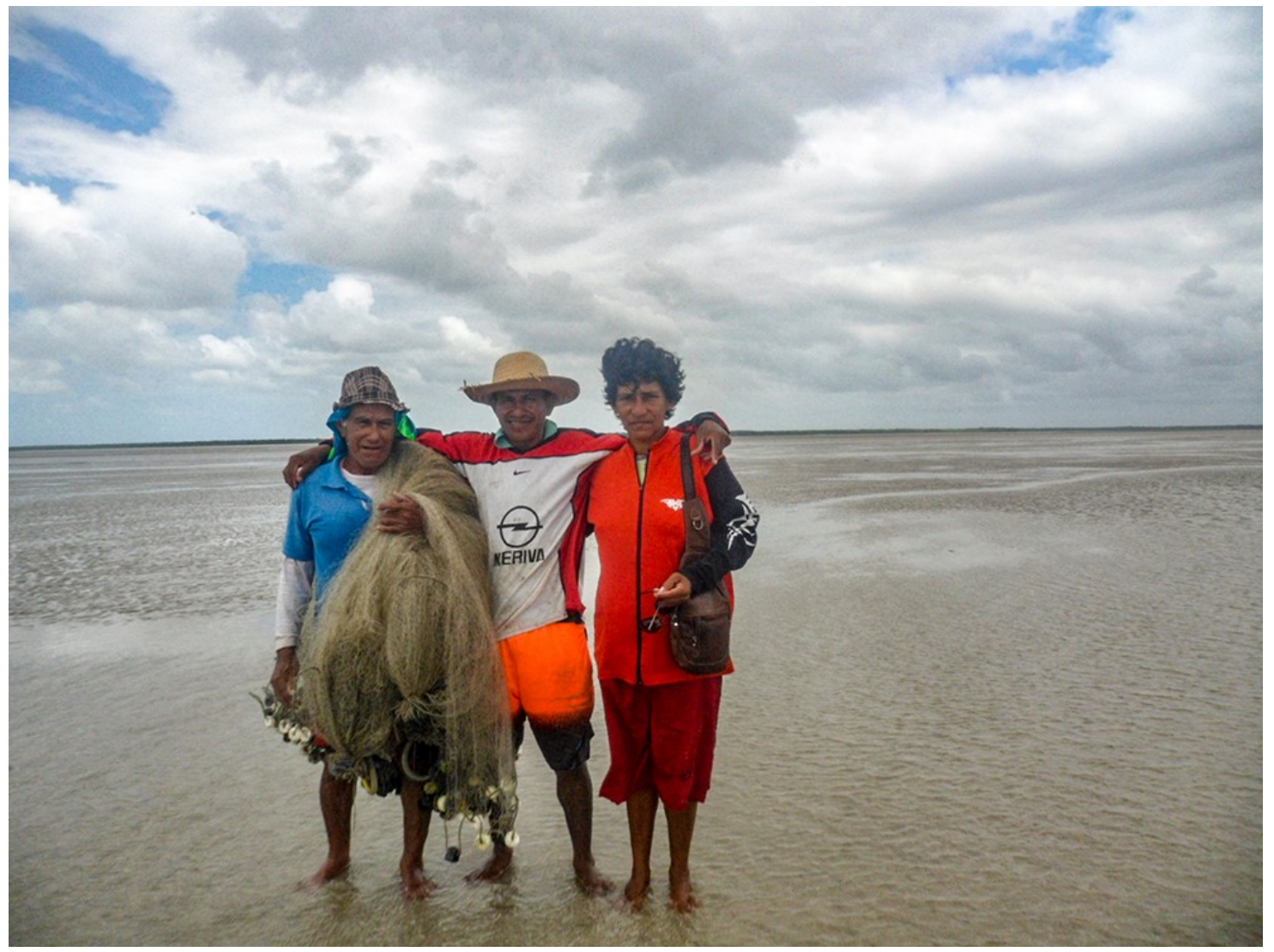

4 Torna-se imperativo frisar que, as fotografias deste ensaio não estão postas como meros objetos ilustrativos sobre o voado, ao contrário, como diria Samain $(2012,2005)$, elas são uma maneira de ver e pensar uma dada realidade sociocultural. Assim, é importante também frisar, que faz algum tempo que a fotografia tornou-se um potente instrumento de coleta de dados, com especificidades que contribuem como "[...] forma de saber ver e saber dizer melhor para fazer pensar por meio da imagem [...]" (SAMAIN, apud ACHUTTI, 2004, p. 83). Em alguns casos, tais especificidades escapam a outras técnicas de coleta. Ela permite ao etnógrafo captar detalhes empíricos que normalmente não se mostram à primeira vista. São detalhes que se escondem por detrás da aparência e que, às vezes, só a fotografia pode revelar. Esses detalhes são aqueles secundários ou marginais, os que não foram ditos, mas que podem ser decisivos para o trabalho do etnógrafo. Assim, as imagens deste ensaio são autônomas, "pensam" e nos fazem pensar sobre o modo singular de comer dos pescadores do rio Araí. 


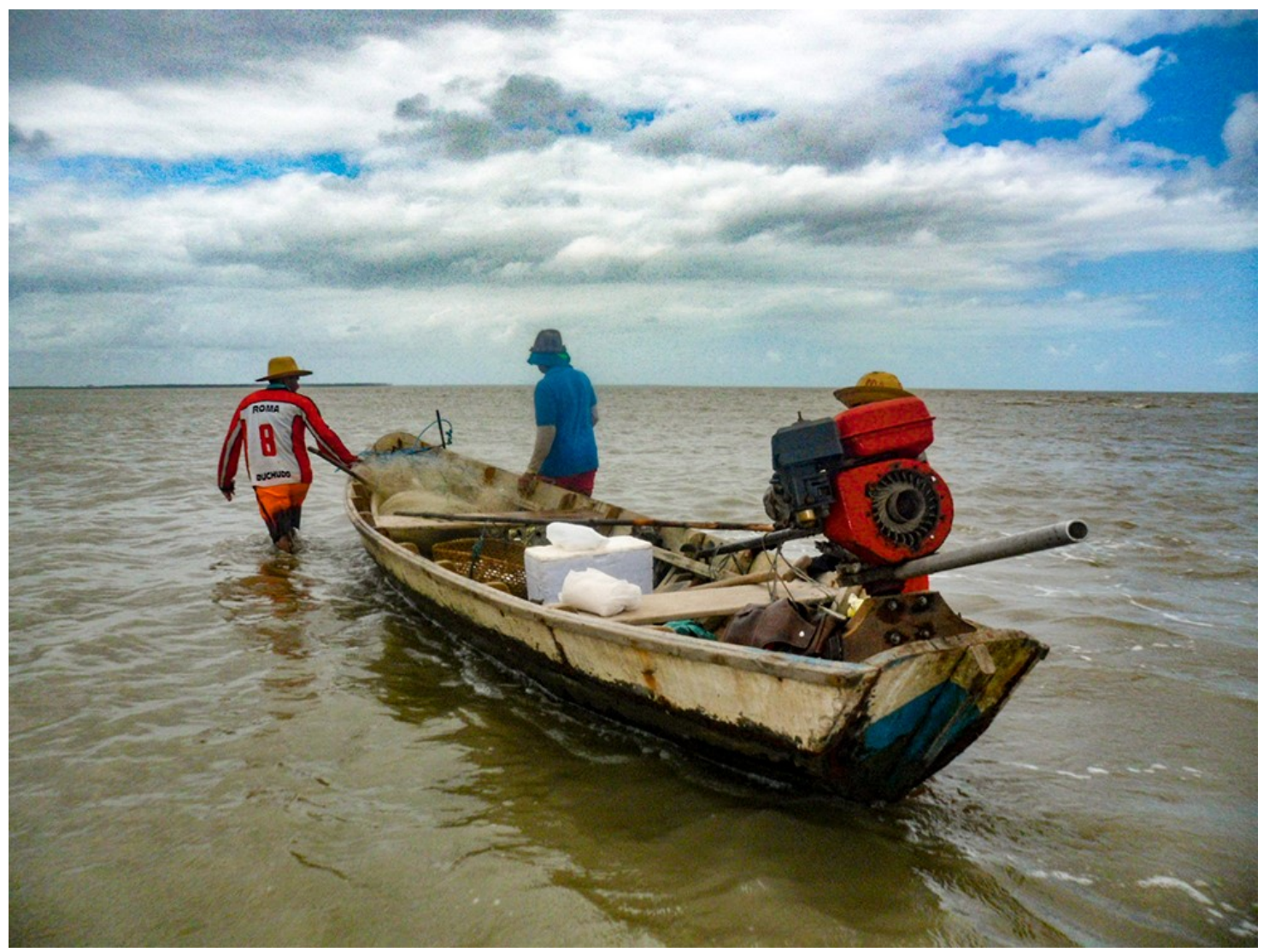




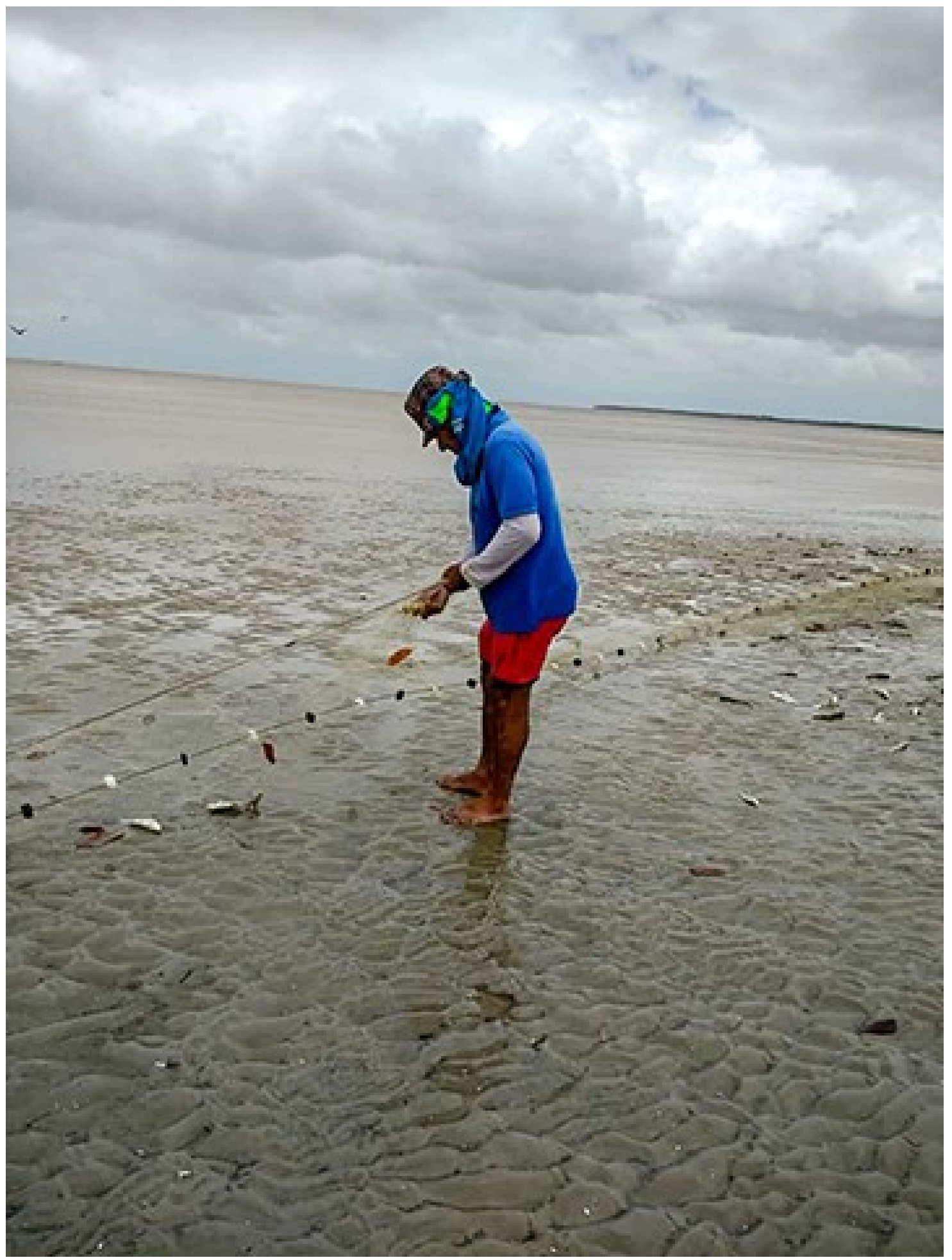




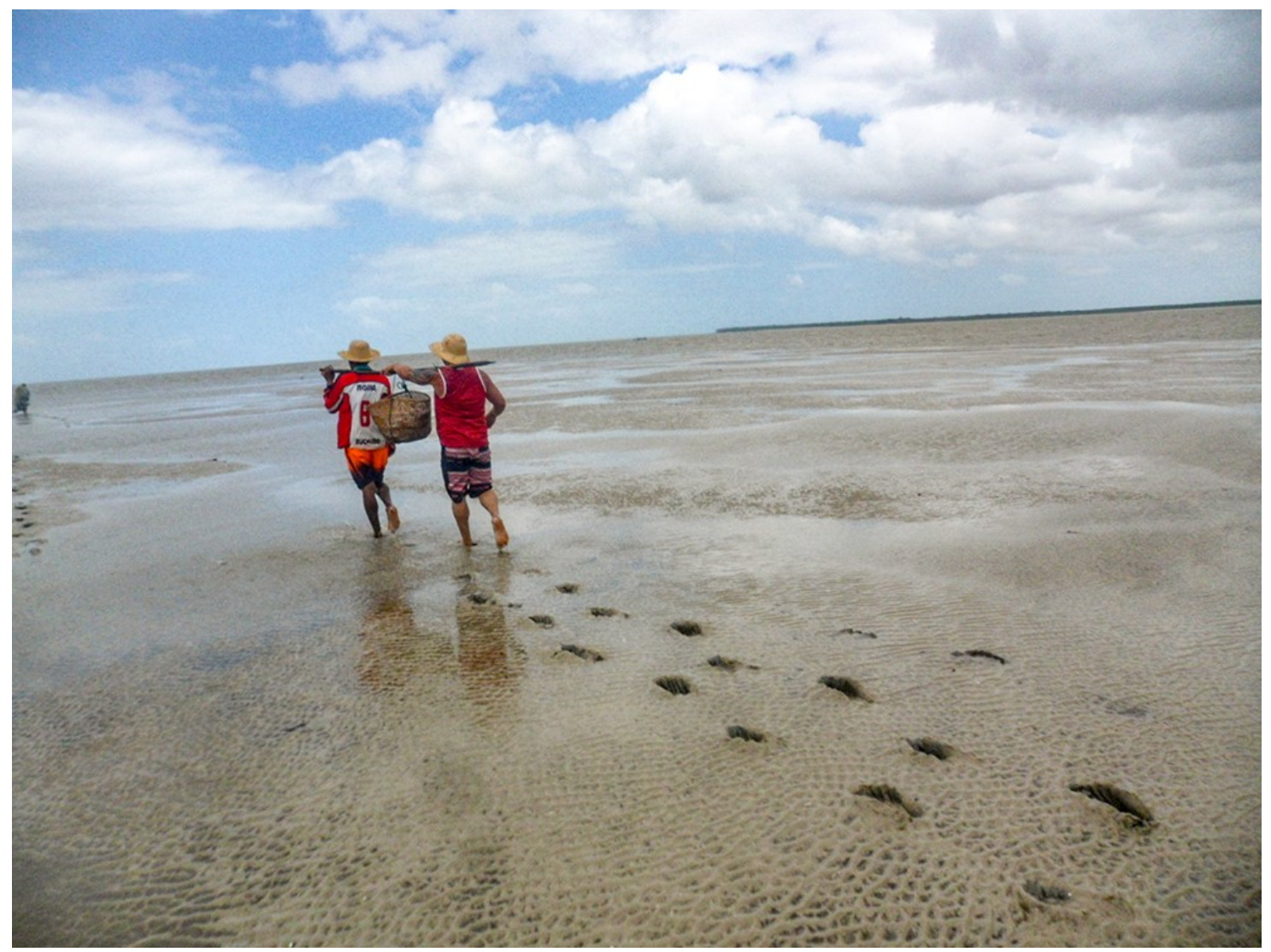




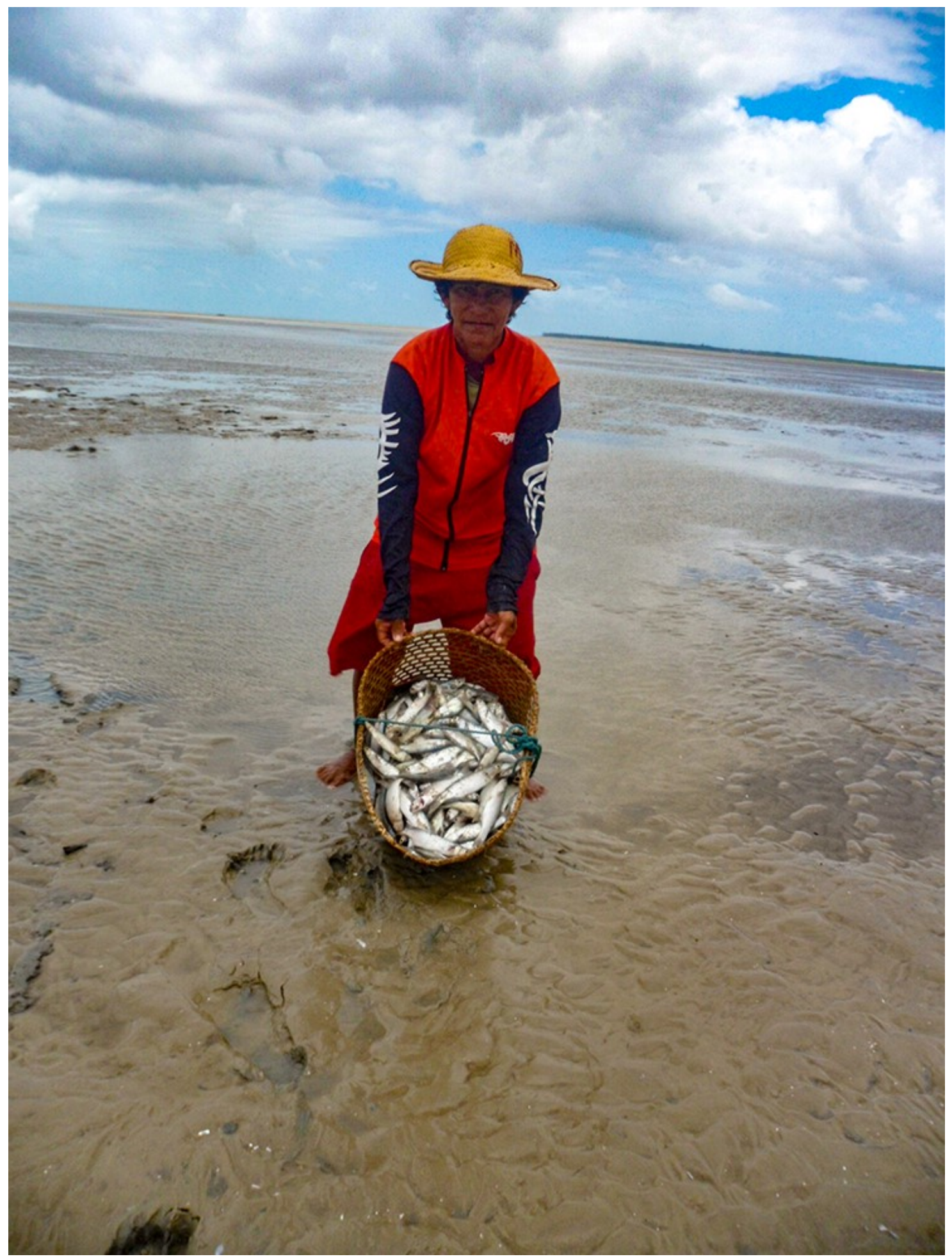




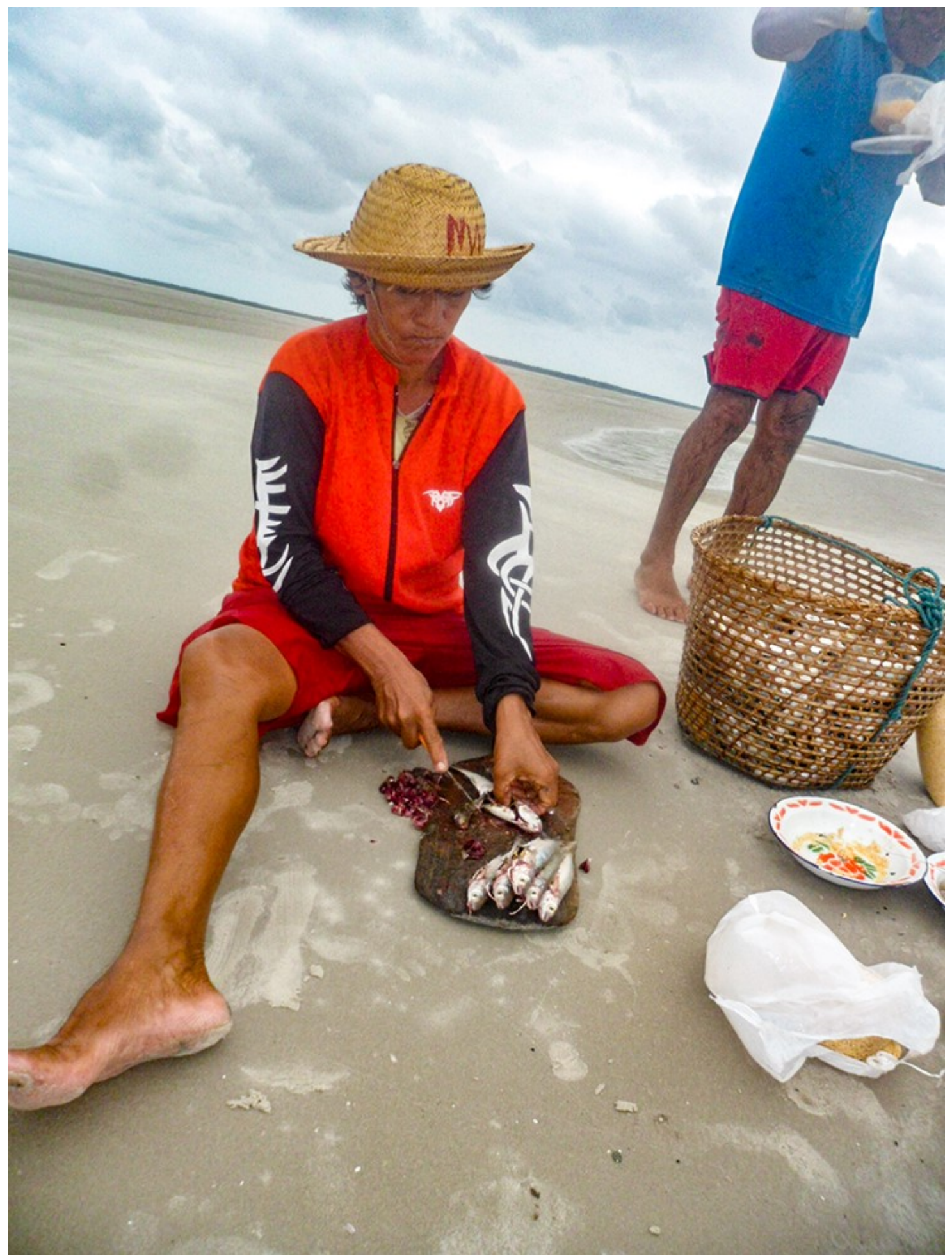



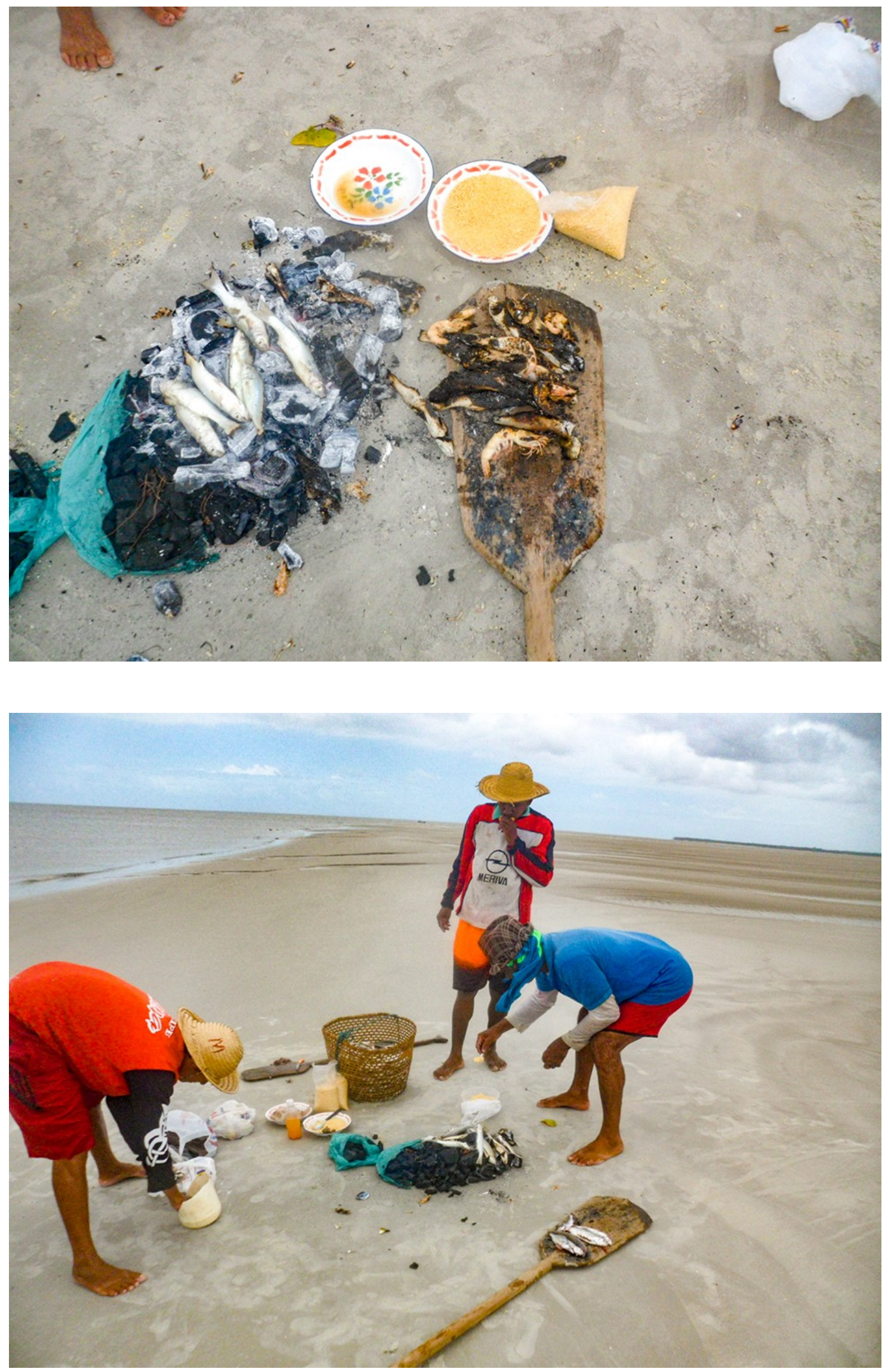

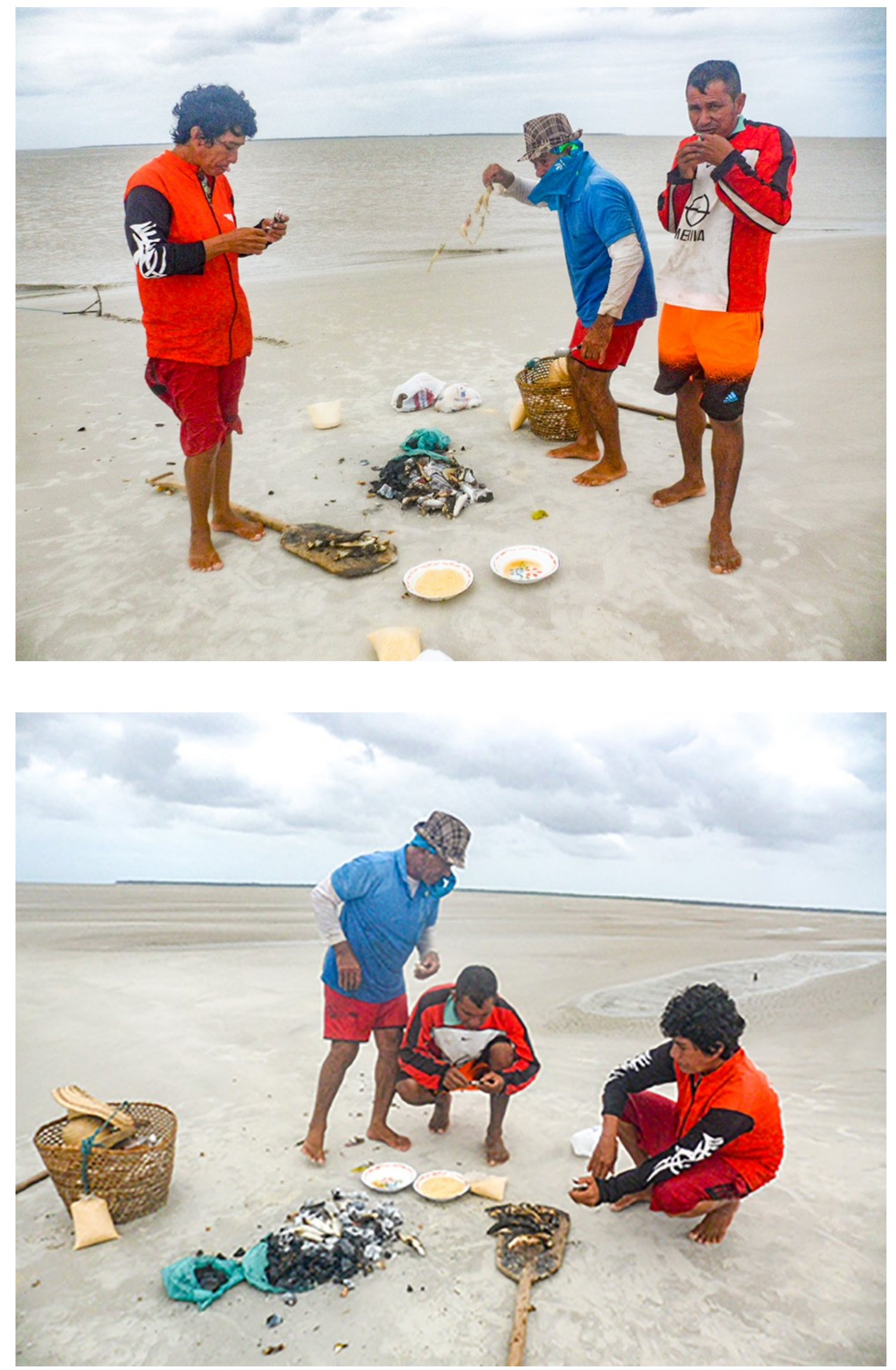


\section{Referências}

ACHUTTI, Luiz Eduardo Robinson. Fotoetnografia da Biblioteca Jardim. Porto Alegre: EDUFRGS, 2004.

CONTRERAS, Jesús. Alimentación y Cultura: reflexiones desde la Antropología. Universidad de Chile. Facultad de Ciências sociales: Revista Chilena de antropología, n. 11, p. 95-111. 1992. Disponível em: <http://www.revistadeantropologia.uchile.cl/>. Acesso em: 3 ago. 2016.

DAMATTA, Roberto. O que faz o brasil Brasil? Rio de Janeiro: Rocco, 1986.

DOUGLAS, Mary; ISHERWOOD, Baron. O mundo dos bens: para uma antropologia do consumo. $1^{\text {a }}$ Ed. Rio de Janeiro: UFRJ, 2006.

MACIEL, Maria Eunice. Olhares antropológicos sobre a alimentação: Identidade cultural e alimentação. In. CANESQUI, AM., and GARCIA, RWD., orgs. Antropologia e nutrição: um diálogo possível [online]. Rio de Janeiro: FIOCRUZ, p. 48-5, 2005. Disponível em: $<$ http://books. scielo.org >. Acesso em: 12 fev. 2016.

PICANÇO, Miguel de Nazaré Brito. Na roça, na mesa, na vida: uma viagem pelas trajetórias da mandioca, no e além do nordeste paraense. Belém: Paka-Tatu, 2018.

PICANÇO, Miguel de Nazaré Brito. Comida, consumo e identidade: Notas etnográficas por entre os processos migratórios da mandioca; do contexto brasileiro e paraense ao contexto europeu. Mosaico, Rio de janeiro, v. 8, n. 13, 2017, p. 203-221. Disponível em: <www.bibliotecadigital,fvg.br>. Acesso em: 18 dez. 2017.

SAMAIN, Etienne. Como pensam as imagens. Campinas, SP: Editora da Unicamp, 2012. SAMAIN, Etienne. O fotográfico. São Paulo: Hucitec/senac, 2005. 